\title{
RESEARCH
}

\section{Repercussion Of Organophosphate Function Prevalence On Pandemic Levels Of Mango Seed Beetle Cryptorhynchus Mangiferae Fabricius}

\author{
Prof. Sn Okoth, Prof. Ha Mathooko \\ Department Of Horticulture ,Chuka University, Kenya
}

\begin{abstract}
Field studies were administrated in 3 sites in Mbeere district to see the impact of prevalence of organophosphate band application on mango fruit pandemic levels by the mango seed beetle Cryptorhynchus mangiferae Fabricius. the target was to assess the impact of organophosphate band application prevalence on the pandemic levels of the Mango seed beetle (MSW) on mango fruits. Four application levels particularly once per month, once each 2 months, once each 3 months and once per mature season were studied. woodlet sanitation was combined with these treatments. organophosphate applied once monthly performed the simplest altogether sites and differed considerably from all the opposite treatments. This performance was consistent altogether months. Effectiveness of organophosphate in reducing mango fruit pandemic levels is part keen about prevalence of application. A closely spaced application regime leads to a better reduction of the pandemic levels. A monthly application of this product within the manner tested seems to allow a big population reduction leading to higher yields of marketable fruits. This regime is suggested for incorporation to the mango farming practices.
\end{abstract}

Key words: Organophosphate, Mango seed beetle, Cryptorhynchus Mangiferae

\section{Introduction}

The Mango seed beetle, S. mangiferae is associate insidious gadfly that spends most of its life cycle within the mango seeds (Pena, et al. 1998). woman weevils oviposit on fruits into boatshaped cavities that they create on the fruit (Anon, 2005; Follet, 2002; Smith, 1996). The larvae burrow through the pulp to the developing seed on hatching. The tunnel created by the larvae 


\section{THE AMERICAN JOURNAL OF}

\section{RESEARCH}

becomes undetectable once a brief time (Joubert, 1998; Woodruff and Fasulo, 2006). the next larval and immature stages occur within the seed (Follet and Gabbard, 2000). The larvae go after the seed and create intensive tunnels on the seed surface. A copious quantity of frass is deposited in these feeding tunnels. The strategy of feeding within the seed capsule makes it tough to manage the gadfly by use of such typical ways as foliar application of chemical pesticides.

Control of this gadfly has been hampered by each its cryptic nature and absence of effective natural enemies. The management approach envisaged during this work is predicated on making a barrier between the resting web site of the insect and therefore the developing fruits and so preventing infestation. the target of this study was to assess the impact of organophosphate band application prevalence on the pandemic levels of the Mango seed beetle (MSW) on mango fruits.

The farmer oversubscribed fruits to each the native and export market retailers. The Karurumo web site on the opposite hand diagrammatical an oversized scale mango woodlet (over a hundred hectares), planted with the elite mango cultivars and active sensible woodlet management. The woodlet oversubscribed most of the fruits to exporters and extremely very little to the native market. The Kanyuambora web site diagrammatical alittle scale mango woodlet (1.0 hectare) planted with the elite mango cultivars however with irregular management practices like weeding, gadfly and unwellness management, fertiliser application etc. All the orchards were pronto accessible; the farmers were willing and had a history of mango seed beetle infestation.

\section{Materials And Ways}

Altogether the 3 sites, the treatment blocks were deliberately organized to line the mango rows so as to eliminate potentialities of mix-ups throughout treatment applications. organophosphate was diluted with water at the speed of $40 \mathrm{ml}$ of economic product in one I of water. The chemical mixture was unreal mistreatment methylthionine chloride to differentiate the treated and untreated mango trees. A $5 \mathrm{~cm}$ wide paint brush was wont to apply a $15 \mathrm{~cm}$ wide band round the fruit tree trunk at a height of $30 \mathrm{~cm}$ from the bottom. 


\section{THE AMERICAN JOURNAL OF}

HORTICULTURE AND FLORICULTURE

VOLUME01 ISSUE05

\section{RESEARCH}

The treatments were as follows: one. organophosphate band applied once per mature season + sanitation a pair of. organophosphate band applied once per month for six months + sanitation three. organophosphate band applied once each a pair of months for six months + sanitation four. organophosphate band applied once each three months for six months five. Sanitation alone (All fallen fruits were collected once per week and buried deeply within the soil) vi. No sanitation, no chemical treatment

The treatments were as follows: one. organophosphate band applied once per mature season + sanitation a pair of. organophosphate band applied once per month for six months + sanitation three. organophosphate band applied once each a pair of months for six months + sanitation four. organophosphate band applied once each three months for six months five. Sanitation alone (All fallen fruits were collected once per week and buried deeply within the soil) vi. No sanitation, no chemical treatmentWhile evaluating spot application of pesticides within the management of Mango seed beetle, Tandon and Shukla (1984) indicated that deltamethrin and carbaryl were the foremost effective within the management of the Mango seed beetle. The pandemic levels in respect of those were thirteen.5 and $14.7 \%$ severally. Sanitation involving weekly assortment of all fallen fruits and seeds reduced pandemic to between five.50 \pm 0.56 and $5.67 \pm 0.14$. This technique is suggested as a very important element in mango seed beetle management.

The once per month application prevalence of organophosphate combined with sanitation is each effective and economical because it reduced the pandemic to terribly low levels (2.02 \pm 0.14 ) and value solely KES five.00 per month (excluding labour) to color one tree. The calculation was supported the actual fact that forty cc of the chemical was wont to paint concerning ten trees which $200 \mathrm{ml}$ of the chemical was priced at KES 250.00 . 


\section{THE AMERICAN JOURNAL OF}

\section{HORTICULTURE AND FLORICULTURE}

\section{VOLUME01 ISSUE05}

\section{RESEARCH}

\section{References}

1. Mustard apple. 2000. necessities for institution of gadfly free space for mango nut (seed) beetle (Sternochetus mangiferae) and Pulp beetle (S. frigidus). Government of Bharat, Ministry of Agriculture.

2. Jollett PA. 2001. Mango seed beetle and premature fruit drop by mangoes. Journal Of Economic zoology, 45: 126-129

3. Fabbard Z. 2001. impact of Mango beetle harm on mango seed viability in Hawaii. Journal of Economic zoology 23:1337-1340.

4. Hill DS. 1985. Agricultural pests of the Tropics and their management. CUP pp 121

5. Joubert PH. 1995. Mango beetle pp 154145. In: The cultivation of the Mangoes. Ed. E.A American state Villiers. Institute for Tropical and climatic zone Crops. ARC-LNR Pp 316.

6. Shukla RP. 1989. Spot application of pesticides for the management of mango stone beetle Sternochetus mangiferae Fabr). Acta Horticulturae 531:871-897 